\title{
SISTEMA DE INFORMAÇÕES GEOGRÁFICAS (SIG) APLICADO AO CÁLCULO DE ÍNDICES MORFOMÉTRICOS EM BACIA HIDROGRÁFICA
}

\section{GEOGRAPHIC INFORMATION SYSTEM (GIS) APPLIED TO THE CALCULATION OF MORPHOMETRIC INDEX IN WATERSHED}

\author{
Marcos Esdras Leite ${ }^{1}$, André Medeiros Rocha ${ }^{1}$ \\ ${ }^{1}$ Universidade Estadual de Montes Claros (Unimontes), Montes Claros, MG, Brasil
}

\author{
Correspondência para: André Medeiros Rocha (andremedeiros197@hotmail.com) \\ doi: $10.12957 /$ geouerj.2016.18520 \\ Recebido em: 11set. 2015 | Aceito em: 16 out. 2015
}

\section{RESUMO}

A Geomorfologia constitui ramo científico que objetiva estudar as formas de relevo, com foco em especial na análise de sua gênese e evolução. Sobre isso, tendo por base as principais teorias sobre a existência da variedade de formas do relevo (como as teorias penckiana e davisiana), Guerra e Guerra (2011) afirma que a ação simultânea ou alternada das forças internas e externas sobre a superfície terrestre é responsável por suas irregularidades. Por sua vez, esse conjunto de formas apresentado pelo relevo desde sua gênese até os dias atuais descreve seu desenvolvimento ou ciclo evolutivo. Com base no exposto e com foco em especial nos estudos geomorfológicos de bacias hidrográficas, Horton (1945) atesta sua preocupação sobre a falta de ferramentas para investigação adequada do nível de desenvolvimento do relevo, julgando que as pesquisas até então eram fundamentalmente baseadas em aspectos qualitativos. Logo, como forma de solução de tais questões, o autor mencionado aconselha o uso de ferramentas quantitativas para estudos mais incisivos sobre o grau de desenvolvimento do relevo. Dessa forma, o presente estudo objetivou analisar o relevo da bacia do rio Vieira,a partir dos índices morfométricos apresentados Christofoletti (1980), tendo por base fundamental os estudos de Horton (1945) e Strahler (1952 e 1957). Para efeito de obtenção das variáveis morfométricas, em ambiente de Sistema de Informação Geográfica (SIG), os dados altimétricos do Modelo Digital de Elevação (MDE) oriundos da missão SRTM foram utilizados como base. Ao final, os índices indicaram, principalmente que a bacia do rio Vieira possui relevo, predominantemente entre o plano ao ondulado, com sistema de drenagem fracamente drenado e atividade erosiva em estágio de estabilidade.

Palavras-chave: Bacia Hidrográfica; Variáveis Morfométricas; SIG; MDE.

\begin{abstract}
The geomorphology constitutes a scientific branch who aims to study the relief forms, with special focus in the analysis of its genesis and evolution. About that, basing in the main theories over the existence of variety of relief forms (as Penck and Davis theories), Guerra and Guerra (2011) state that the simultaneous or alternating action of the internal and external forces over the surface are responsible for its irregularities. Thereafter, this set of forms presented by relief since its genesis until present day describe its development or evolution cycle. Based on the above and with special attention on the geomorphological studies of drainage basins, Horton (1945) attests his worrying about the lack of tools for adequate investigation of the level of relief development, judging that the researches so far were based fundamentally in qualitative aspects. So, in order to fix such questions, the mentioned author advises the use of quantitative tools for more incise studies over the level of relief development. In that way, the present paper aims to analyze the relief of Vieira river drainage basin through morphometric indices presented by Christofoletti (1980), having as fundamental base the studies of Horton (1945) and Strahler (1952 and 1957). In order to obtain the morphometric variables, in Geographic Information System (GIS) environment, the altimetry data of Digital Elevation Model (DEM) from SRTM mission were used as base. At end, the indexes indicated mainly that the Basin of Vieira River has relief predominantly between flat and wavy, with a drainage system weakly drained and erosive activity in stability stage.
\end{abstract}

Keywords: Drainage Basin; Morphometric Variables; GIS; DEM. 


\section{INTRODUÇÃO}

Os estudos geomorfológicos constituem ramo científico que se propõe a análise das formas do relevo, com foco em especial a sua gênese e evolução. Sobre isso, os escritos de Guerra e Guerra (2011) expõem as premissas que justificam a variedade de formas e modelados que a superfície terrestre apresenta. As mais contundentes e incisivas, como as teorias penckianas e davisianas que lideram as pesquisas na geomorfologia, afirmam a existência de forças ou fenômenos, sejam eles exógenos ou endógenos, de ocorrência simultânea ou alternada que agem sobre a superfície e, consequentemente provocam seus desnivelamentos. As variadas formas pela qual o relevo terrestre passa desde a sua gênese a sua fisionomia atual descrevem etapas que cronologicamente descrevem seu ciclo evolutivo ou de desenvolvimento.

Com relação às informações apresentadas, e com foco ao estudo geomorfológico de bacias de drenagem, Horton (1945) expõe sua preocupação sobre a falta de técnicas para adequada investigação do desenvolvimento das formas do relevo, julgando as pesquisas em tal área fundamentadas até então principalmente em aspectos qualitativos. Sobre isso, o referido autor sugere a utilização de técnicas de cunho quantitativo para investigação e estudo mais incisivo dos níveis de desenvolvimento do relevo. Nesse ponto, Florenzano (2008) refere-se às técnicas mencionadas por Horton (1945) como constituindo a morfometria, ramo da morfologia, a qual utiliza de um conjunto de variáveis e índices quantitativos para análise do relevo.

No que concerne aos métodos utilizados para extração de tais variáveis, Klinkenberg, Schiefer e Ham (2006) destacam que tradicionalmente as propriedades morfométricas eram determinadas a partir de mapas topográficos, com uso exclusivo de métodos manuais. Os anos posteriores a década de 1960, por outro lado, presenciaram o surgimento e desenvolvimento dos Sistemas de Informações Geográficas (SIGs), o qual se constituiu como fator determinante para automatização de tarefas no âmbito dos estudos geomorfológicos. Nesse contexto, dentre a vasta potencialidade operacional oferecida pelos SIGs, os referidos autores destacam, entre outras, a extração automática de parâmetros morfométricos, o monitoramento da evolução de fenômenos, a realização de mapeamentos 
em diversas escalas e a análise integrada de dados provenientes de variadas fontes como requisitos fundamentais no âmbito dos estudos morfométricos.

Logo, diante das possibilidades de estudos de cunho morfométrico existentes, o presente artigo ${ }^{1}$ objetivou analisar o relevo da Bacia do Rio Vieira², localizada no município de Montes Claros - MG, a partir dos parâmetros morfométricos sugeridos por Christofoletti (1980). A escolha da literatura acima se fundamenta no fato do referido autor propor uma sistematização de parâmetros e índices para análise de bacias hidrográficas. Nessa proposição, são utilizados índices sugeridos inicialmente por Horton (1945) e Strahler (1952 e 1957) ${ }^{3}$, os quais constituem os primeiros esforços na definição de leis do desenvolvimento de bacias de drenagem.Para efeito de atingir o objetivo proposto, os índices morfométricos serão calculados a partir dos dados altimétricos do Modelo Digital de Elevação (MDE) oriundo da missão Shuttle Radar Topographic Mission (SRTM) que serão manipulados em ambiente do Sistema de Informação Geográfica (SIG) ArcGIS 10.2.1

\section{MATERIAIS E MÉTODOS}

\section{Caracterização da Área}

Localizada no município de Montes Claros, na Mesorregião Norte do Estado de Minas Gerais, a bacia do Rio Vieira situa-se entre as coordenadas geográficas $16^{\circ} 32^{\prime} 30^{\prime \prime}$ e $16^{\circ} 51^{\prime} 10^{\prime \prime}$ de Latitude S e $43^{\circ}$

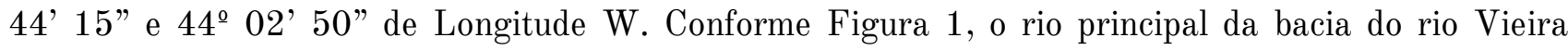
constitui afluente de margem esquerda do Rio Verde Grande e subafluente de margem direita do Rio São Francisco.

\footnotetext{
${ }^{1}$ A presente pesquisa consiste numa versão ampliada e aprofundada do artigo intitulado Análise Morfométrica da Bacia do Rio Vieira (ROCHA, MORAIS e LEITE, 2015), a qual fora publicado no XVII Simpósio Brasileiro de Sensoriamento Remoto.

${ }^{2}$ A escolha da Bacia do Rio Vieira fundamenta-se no fato desta constituir uma das áreas de investigação direta que o Laboratório de Geoprocessamento da Universidade Estadual de Montes Claros vem efetuando estudos. Além disso, corrobora para essa escolha o fato da cidade de Montes Claros ocupar considerável parte dessa bacia.

3 Embora não consultado diretamente, cabe indicar nesse ponto os parâmetros morfométricos sugeridos por Melton (1958), Miller (1953) e Schumm (1956) na análise do processo de desenvolvimento de bacias hidrográficas.
} 


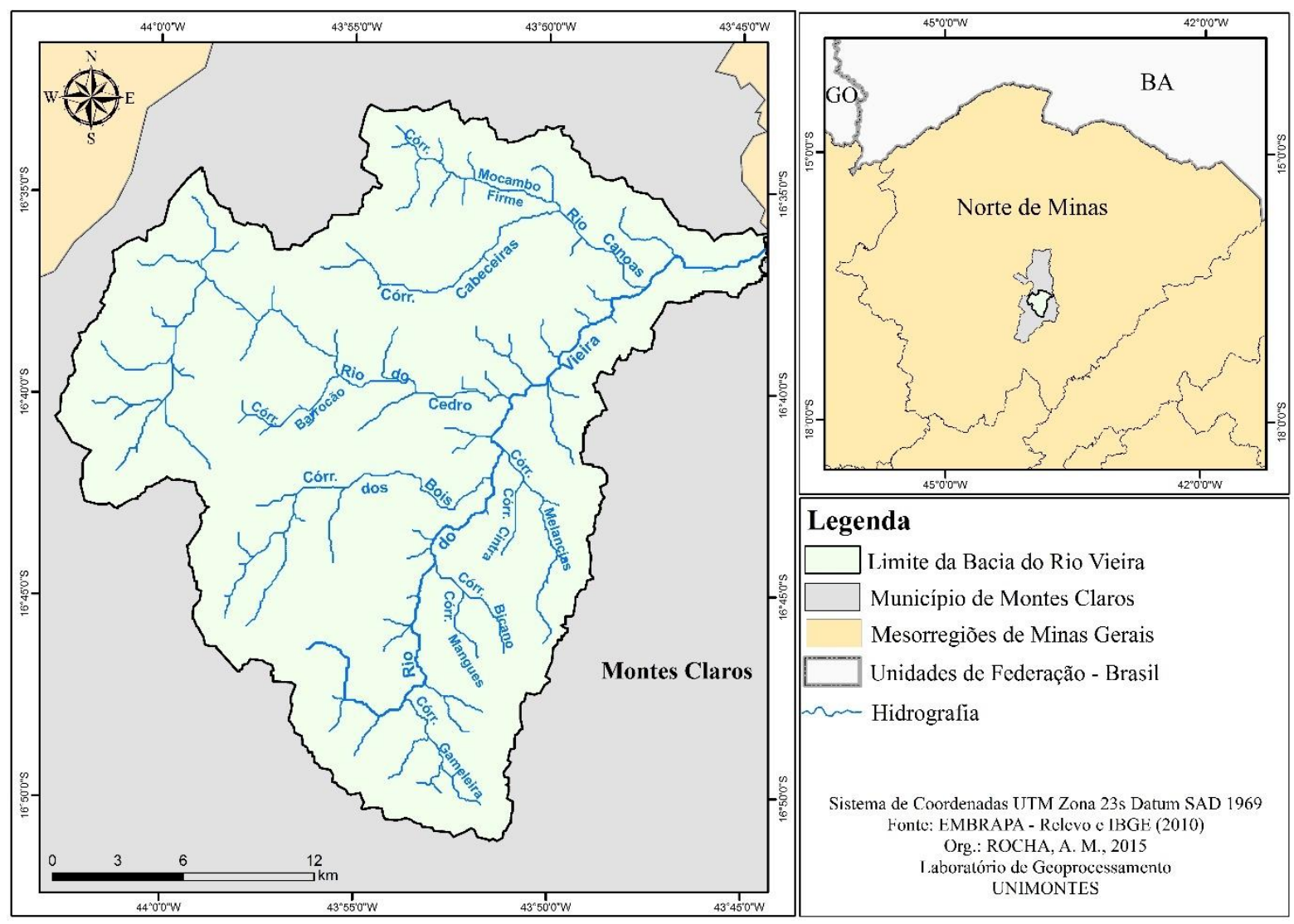

Figura 1. Localização da Bacia do Rio Vieira.

\section{Materiais e métodos}

Com intuito de realização da análise morfométrica da bacia do rio Vieira, a presente pesquisa utilizou como base para extração e validação da rede de drenagem e cálculo dos parâmetros morfométricos os seguintes materiais e softwares:

- Modelo Digital de Elevação (MDE) da missão Shuttle Radar Topographic Mission (SRTM) de resolução espacial de 90m (Folha SE-23-X-A) disponível para download pela EMPRAPA relevo;

- Mapa Municipal Digital de Montes Claros de escala 1:100.000 do Instituto Brasileiro de Geografia e Estatística - IBGE (2010);

- Software ArcGIS 10.2.1 para procedimentos operacionais envolvendo base de informações geográficas e confecção de mapas;

- Software Microsoft Office Excel 2007 para tabulação 
Considerando os materiais utilizados, a pesquisa foi dividida substancialmente em 3 etapas, sendo a 1 a . Delimitação da bacia hidrográfica; 2a . Extração dos canais de Drenagem; e $3^{\text {a }}$. Cálculo das variáveis morfométricas.

Para efeito de delimitação da bacia do rio Vieira ( $1^{\text {a }}$ etapa), inicialmente aplicou a metodologia indicada por Valeriano et al. (2006) para reamostragem do dado SRTM para resolução espacial de 30m. Por conseguinte, a extração da bacia de drenagem seguiu a metodologia presente no trabalho de Jenson e Domingue (1988). Nesse método, o MDE-base é inicialmente submetido a um processo de correção hidrológica, em que as depressões ou células com fluxo de direção indefinido (sinks) são preenchidas para efeito de correção da drenagem. Logo, o MDE (nessa etapa, chamado Depressionless $M D E)$ é utilizado para geração do Fluxo de Direção (Flow Direction), no qual cada célula será associada a uma das 8 possíveis orientações que o escoamento pode ser direcionado. Por conseguinte, utilizando o produto anterior, o Fluxo de Acumulação (Flow Accumulation) é gerado e, então, cada célula da matriz é associada a quantidade de células que confluem ou convergem para ela. Nesse momento, é identificado o ponto de menor altitude da bacia (Pour Point) que corresponde, por sua vez à célula de maior fluxo acumulado. A delimitação da bacia, por fim, é realizada a partir do comando watershed,o qual considera o fluxo de direção de cada pixel.

$\mathrm{Na} 2^{\mathrm{a}}$ etapa, foi realizada a identificação dos canais pertinentes a rede de drenagem. Como o limiar para definição do fluxo de acumulação que melhor represente a rede de drenagem da bacia de estudo não ser bem conhecida, o presente estudo utilizou como parâmetro para identificação dos canais o mapa municipal de Montes Claros de escala 1:100.000, de tal forma que buscou-se ao final um limiar que fosse compatível com a rede de drenagem do mapa-base. Sendo assim, obteve-se um fluxo acumulado de 2.120 células, correspondendo ao limiar para definição dos canais. Tal metodologia, aliás, é discutida em Cherem (2008) e utilizada em Ruszkiczay-Rudiger (2007). A preocupação na definição de tal limiar reside no fato de aplicação da análise morfométrica proposta por Christofoletti (1980) ser direcionada para canais de escoamento fluvial, isto é, canais que estejam nitidamente delineados na superfície. Nesse ponto, deve-se frisar que a inclusão de quaisquer canais na análise pode resultar em resultados morfométricos que não descrevem com fidelidade o relevo da área. 
Para cálculo das variáveis morfométricas, correspondendo a $3^{\text {a }}$ etapa, optou-se nessa pesquisa pelo emprego da metodologia proposta por Christofoletti (1980), pelo fato do mesmo sugerir a divisão da análise morfométrica em 4 itens fundamentais: sejam eles 1) Hierarquia Fluvial; 2) Análise Linear; 3) Análise Areal e 4) Análise Hipsométrica.De outro modo, cabe ressaltar que além da literatura mencionada, foram utilizados os trabalhos de Horton (1945) e Strahler (1952 e 1957), uma vez que esses autores constituemreferências fundamentais na análise morfométrica de bacias hidrográficas.

A Hierarquia Fluvial (Hf) constituiu o $1^{\circ}$ item de análise e, nesse estudo, optou-se pela adoção do método de classificação dos canais apresentados por Strahler (1952). No respectivo método, os canais de $1^{\text {a }}$ ordem são os menores tributários; não apresentando, portanto, afluentes. Os canais de $2^{\text {a }}$ ordem são formados pela confluência de dois canais $1^{\text {a }}$ ordem. $\mathrm{O}$ ordenamento dos demais canais de ordens superiores $\left(3^{\mathrm{a}}, 4^{\mathrm{a}}, 5^{\mathrm{a}}\right.$ etc) ocorre de tal forma que cada canal de ordem superior se forma a partir da confluência respectiva de dois canais de ordem imediatamente inferiores.

$\mathrm{Na}$ Análise Areal, serão calculados índices morfométricos que se referem principalmente a características pertinentes a rede de drenagem da bacia do rio Vieira. Logo, a referida análise contemplou as variáveis: Relação de Bifurcação $(R b)$, Relação do Comprimento Médio dos Canais $(R l m)$, Relação do Gradiente dos Canais $(R g c)$, Extensão do Percurso Superficial $(E p s)$ e Índice de Sinuosidade $(I s)$.

A $1^{\text {a }}$ Lei de Horton (1945) estabelece que o número de canais das várias ordens que constitui uma bacia de drenagem segue aproximadamente uma série geométrica inversa, na qual o $1^{0}$ termo da sequência é a $1^{\text {a }}$ ordem. Dessa forma, a premissa apresentada conclui que o número de canais de uma dada bacia decresce das ordens inferiores para as superiores. Amparada em tal lei, a Relação de Bifurcação $(\boldsymbol{R} \boldsymbol{b})$, equação $(1)$, representa a razão entre o número de canais de uma dada ordem $\left(N_{u}\right)$ e o número de segmentos da ordem imediatamente superior $\left(N_{u+1}\right)$. Os estudos realizados por Horton (1945) apontaram que valores próximos a 2 remetem a superfícies planas ou levemente onduladas, enquanto índices maiores que 3 ou 4 se referem a áreas inclinadas ou altamente dissecadas. 
A $2^{a}$ Lei de Horton (1945) determina que o comprimento médio dos canais das várias ordens que compõe uma bacia hidrográfica segue aproximadamente uma série geométrica direta, sendo o $1^{0}$ termo da sequência os canais de $1^{\text {a }}$ ordem. Assim, de forma inversa em relação ao sentido de aumento do número de segmentos e declividade dos canais, o comprimento tende a ser maior nas ordens superiores (próximos a foz), em relação aos canais de ordens inferiores (próximos às nascentes).Nesse sentido, a Relação do Comprimento Médio dos Canais (RIm), equação (2), surge como resultante da lei enunciada e se refere à razão existente entre o comprimento médio dos canais de determinada ordem $\left(L m_{u}\right)$ e o comprimento médio dos canais de ordem imediatamente inferior $\left(L m_{u-1}\right)$.

$$
R L m=\frac{L m_{u}}{L m_{u-1}}
$$

Baseando-se em estudos de Playfair, Horton (1945) enuncia a $3^{\text {a }}$ Lei da composição de drenagem na qual a declividade dos canais tende a seguir aproximadamente uma série geométrica inversa, tendo por $1^{\underline{0}}$ termo os canais da $1^{\mathfrak{a}}$ ordem. Em outros termos, a citada lei permite aferir que a declividade dos canais próximos às nascentes (canais de ordem inferior) tende a ser maior (ou relevo é mais inclinado) em relação aos cursos próximos a foz (canais de ordem superior). Logo, partindo-se de tal lei, a Relação do Gradiente dos Canais $(\boldsymbol{R g} \boldsymbol{c})$ refere-se à razão entre a declividade média dos canais de dada ordem $\left(G c_{u}\right)$ e a declividade média dos canais de ordem imediatamente superior $\left(G c_{u+1}\right)$, conforme indicado pela equação (3):

$$
R g c=\frac{G c_{u}}{G c_{u+1}}
$$

Conforme apresentado por Horton (1945), a Extensão do Percurso superficial (Eps) constitui uma das mais importantes variáveis morfométricas que descreve o grau de desenvolvimento do sistema de drenagem duma bacia hidrográfica. 0 referido índice descreve o comprimento do trajeto superficial a 
ser percorrido pelo escoamento desde o interflúvio até o ponto de concentração no canal e, por isso, partindo-se da equação (4), observa-se que Eps é igual ao inverso do dobro da Densidade de Drenagem (Dd). A equação traduz o relacionamento inverso entre Eps e Dd, no qual valores elevados de Eps estão associados a baixos valores de Dd ou mais precisamente de Lt. De outro modo, valores baixos de Eps referem-se a elevadas Dd.

$$
E p s=\frac{1}{2 D d}
$$

O Índice de Sinuosidade (IS), por sua vez, é descrito por Christofoletti (1980) como parâmetro utilizado para distinção entre os canais meândricos e os que não são. A equação (5) mostra que o referido parâmetro constitui o quociente do comprimento total do canal principal $(L)$ pela distância vetorial $(D v)$ dos pontos extremos do curso principal. Lana, Alves e Castro (2001) afirmam que valores próximos a 1 associam a canais retilíneos, ao passo que valores superiores a 2 se referem a canais tortuosos.

$$
I S=\frac{L}{D v}
$$

Tendo por parâmetro em comum a área da bacia do rio Vieira, a Análise Linear ( $3^{\circ}$ item) contempla os índices: Índice de Circularidade $(I c)$, Densidade de Drenagem $(D d)$ e Coeficiente de Manutenção $(C m)$.

Dentre os mecanismos utilizados para identificação da forma aproximada de bacias hidrográficas, fundamentando-se em Miller (1953), Christofoletti (1980) sugere o uso do Índice de Circularidade (Ic) por denotar menor subjetividade nos cálculos. Nesse índice, a equação (6),o parâmetro consiste na razão entre a área da bacia $\left(A_{b}\right)$ e a área do círculo de mesmo perímetro da bacia $\left(A_{c}\right)$. Os estudos de Lana, Alves e Castro (2001) descrevem que índices superiores a 0,51 são típicos de bacias circulares e, por sua vez propícias a ocorrência de cheias; valores inferiores a 0,51 , por outro lado estão atrelados a bacias mais alongadas que, por conseguinte, notabilizam-se por facilitar o escoamento. 


$$
\text { Ic }=\frac{A_{b}}{A_{c}}
$$

No que se refere ao grau de desenvolvimento hidrológico de bacias de drenagem, assim como a Eps, a Densidade de Drenagem (Dd), equação (7),constitui útil parâmetro para avaliação de tal característica, uma vez que considerando a razão entre o comprimento total dos canais fluviais de uma bacia $(L t)$ e sua Área total $\left(A_{b}\right)$, permite averiguar a superfície drenada por unidade de área e,dessa forma, transparecer a capacidade de determinada bacia em gerar e manter cursos fluviais. Nesse ponto, Villela e Mattos (1975) informam que valores próximos a 0,5 km/ $\mathrm{km}^{2}$ caracterizam bacias fracamente drenadas, enquanto índices superiores a $3,5 \mathrm{~km} / \mathrm{km}^{2}$ são típicas de unidades excepcionalmente bem drenadas. Acerca da variação do referido índice, Horton (1945) aponta que os principais fatores que governam sua variação são a precipitação, o relevo, a capacidade de infiltração da superfície e a resistência a atividade erosiva.

$$
D d=\frac{L_{t}}{A_{b}}
$$

Associado a Dd, o Coeficiente de Manutenção (Cm) é apontado por Christofoletti (1980) como indicador da área mínima $\left(\mathrm{m}^{2}\right)$ necessária para manutenção de cada metro de canal fluvial da bacia hidrográfica. A equação (8) apresenta o mencionado índice, no qual consiste no inverso da densidade

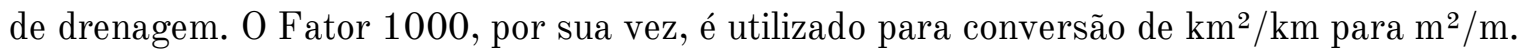

$$
C m=\frac{1}{\mathrm{Dd}} \times 1000
$$

O $4^{\underline{0}}$ item da análise morfométrica constitui a análise hipsométrica, e nesse sentido, engloba as variáveis que têm como parâmetro elementar a hipsometria da bacia do rio Vieira. Tais índices são: a Relação de Relevo $(R r)$, o Índice de Rugosidade (Ir), a Amplitude Hipsométrica $(\Delta H)$, a Altitude Máxima $\left(H_{m a x}\right)$ e Mínima $\left(H_{m i n}\right)$, Curva Hipsométrica e Declividade $(D)$. 
Considerando-se os desníveis e irregularidades da superfície terrestre, os diversos valores de altitude que compõem determinada área perfazem a sua Altimetria. Conforme Guerra e Guerra (2011), o conhecimento de determinadas informações constitui relevante requisito nos estudos geomorfólogos direcionados a interpretação das formas do relevo. Sendo assim, tratando-se de unidades geográficas bem definidas, como as bacias de drenagem, a altitude máxima $\left(\boldsymbol{H}_{\text {máx }}\right)$ e mínima $\left(\boldsymbol{H}_{\text {mín }}\right)$ pode ser facilmente inferida e de outro modo permite a análise da variação altimétrica máxima registrada dentro de determinado perímetro. Essa diferença entre $\mathrm{H}_{\text {máx }}$ e $\mathrm{H}_{\text {mín }}$ corresponde a Amplitude Altimétrica $(\boldsymbol{\Delta} \boldsymbol{H})$. Entretanto, estudos recentes apontam para análises mais complexas que permitem a avaliação da distribuição da massa rochosa ainda existente sobre a superfície, a qual, naturalmente, está sujeita a ação dos agentes exógenos.

Com base no exposto, Strahler (1952 e 1957) sugere a utilização de Curvas Hipsométricas como mecanismo para avaliação do estágio ou fase dos processos erosivos de determinada área. A Figura 2 ilustra a Curva Hipsométrica em unidades percentuais. Embora seja possível a confecção em unidades absolutas, o referido autor aconselha a utilização dos dados em \% por permitir a comparação de bacias de dimensões territoriais e altimétrica diferentes. Nesse sentido, conforme a Figura 2, no eixo das ordenadas, tabula-se a razão entre a altitude em relação ao nível de base da bacia hidrográfica e a amplitude altimétrica. Em consequência, os valores do eixo y com variação entre 0 a 1 correspondem respectivamente ao nível de base da bacia $\left(H_{m i n}\right)$ e a altitude máxima registrada $(\Delta H)$. Assim, paralelamente a cada uma das faixas altimétricas definidas em relação ao nível de base, no eixo x, tabula-se valores que representam a área existente acumulativa acima de cada uma das faixas altimétricas. A curva hipsométrica então traçada da bacia representa uma curva acumulativa das terras emersas desde o seu nível de base (onde $\mathrm{x}=1$ e $\mathrm{y}=0$ ) até $\mathrm{o}$ ponto de maior elevação da bacia (onde $\mathrm{x}=0$ e $\mathrm{y}=1$ ). 


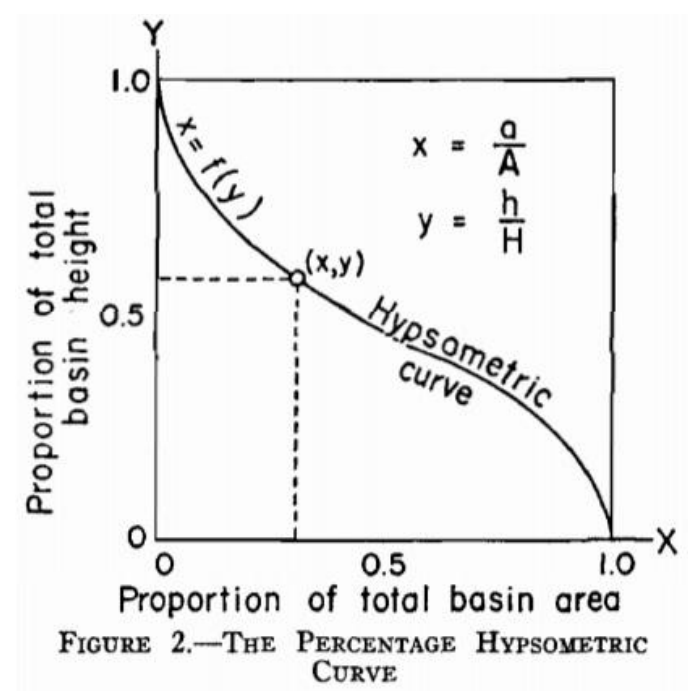

Figura 1. Curva Hipsométrica de Strahler (p. 1120, 1952).

Partindo de tais informações, do ponto de vista hipsométrico, Strahler (1952) reconhece a existência de dois estágios do ciclo erosivo: o de Desequilíbrio, representado por curvas convexas, em que o sistema de drenagem é incipiente e está em expansão e o de Equilíbrio, em que a curva apresenta caráter próximo ao côncavo e características inversas às anteriores.

Conforme Christofoletti (1980), a Relação de Relevo (Rr), equação (9),refere-se a razão entre a Amplitude Altimétrica $(\Delta H)$ e o Comprimento da bacia $\left(L_{b}\right)$.

$$
R r=\frac{\Delta \mathrm{H}}{L_{b}}
$$

O Índice de Rugosidade (Ir), equação (10), é apontado por Christofoletti (1980) como produto da Amplitude Altimétrica $(\Delta H)$ pela Densidade de Drenagem $(D d)$. Conforme o mencionado autor, o parâmetro apresentado descreve a relação entre a declividade e o comprimento das vertentes, sendo indicada a análise conjunta dos fatores da multiplicação para compreensão do produto. Dessa forma, valores baixos ou elevados de Ir ocorrem somente quando ambos os fatores apresentarem mesmo comportamento.

$$
I r=\Delta \mathrm{H} \times \mathrm{Dd}
$$

\section{RESULTADOS E DISCUSSÃO}


Conforme enunciado anteriormente, a análise morfométrica seguirá a divisão proposta por Christofoletti (1980). Para efeito de análise da Hierarquia fluvial, será utilizada a Figura 2. Os índices morfométricos a serem discutidos nas Análises Areais, Lineares e Hipsométricas estão sintetizados na Tabela 1.

Tabela 1. Síntese dos Indicados Morfométricos da bacia do rio Vieira.

\begin{tabular}{|c|c|c|c|c|c|}
\hline Hf (Strahler, 1952) & $\begin{array}{c}\mathrm{N}^{\mathrm{o}} \mathrm{de} \\
\text { Segmentos }\end{array}$ & $\begin{array}{c}\text { Comprimento } \\
\text { Médio dos } \\
\text { Canais }\end{array}$ & $\begin{array}{c}\text { Comprimento } \\
\text { Total dos } \\
\text { Canais }\end{array}$ & \multicolumn{2}{|c|}{ Declividade Média dos Canais } \\
\hline $1^{\text {a }}$ Ordem & 85 & $1,75 \mathrm{~km}$ & $148,56 \mathrm{~km}$ & \multicolumn{2}{|c|}{$3,55 \%$} \\
\hline $2^{\text {a }}$ Ordem & 43 & $1,68 \mathrm{~km}$ & $72,18 \mathrm{~km}$ & \multicolumn{2}{|c|}{$2,97 \%$} \\
\hline $3^{\text {a }}$ Ordem & 30 & $1,86 \mathrm{~km}$ & $55,70 \mathrm{~km}$ & \multicolumn{2}{|c|}{$2,23 \%$} \\
\hline $4^{\mathrm{a}}$ Ordem & 11 & $1,55 \mathrm{~km}$ & $17,09 \mathrm{~km}$ & \multicolumn{2}{|c|}{$0,74 \%$} \\
\hline$R b-1^{\mathrm{a} / 2^{\mathrm{a}}}$ & 1,98 & $\operatorname{Rlm}-4^{\mathrm{a} / 3^{\mathrm{a}}}$ & 0,84 & $\overline{D d}$ & $0,506 \mathrm{~km} / \mathrm{km}^{2}$ \\
\hline$R b-2^{\mathrm{a}} / 3^{\mathrm{a}}$ & 1,43 & $\operatorname{Rlm}-3^{\mathrm{a} / 2^{\mathrm{a}}}$ & 1,11 & $\mathrm{Cm}$ & $1.976,35 \mathrm{~m}^{2} / \mathrm{m}$ \\
\hline$R b=3^{\mathrm{a} / 4^{\mathrm{a}}}$ & 2,73 & $\operatorname{Rlm}-2^{\mathrm{a}} / 1^{\mathrm{a}}$ & 0,96 & Abacia & $580,14 \mathrm{~km}^{2}$ \\
\hline $\operatorname{Rgc}-1^{\mathrm{a}} / 2^{\mathrm{a}}$ & 1,20 & Eps & 0,988 & Cbacia & $33,43 \mathrm{~km}$ \\
\hline $\operatorname{Rgc}-2^{\mathrm{a}} / 3^{\mathrm{a}}$ & 1,33 & Is & 1,6 & $R r$ & $14,11 \mathrm{~m} / \mathrm{km}$ \\
\hline $\operatorname{Rgc}-2^{\mathrm{a} / 3^{\mathrm{a}}}$ & 3,01 & $I c$ & 0,359 & Ir & 238,82 \\
\hline
\end{tabular}

Fonte: SRTM, 2000.

\section{Hierarquia fluvial}

Com relação ao ordenamento dos Canais, tendo por embasamento a classificação hierárquica de Strahler (1952), a Figura 3 demonstra que a bacia de estudo apresenta ordenamento de $4^{\text {a }}$ ordem, sendo que a $1^{\text {a }}, 2^{\mathrm{a}}, 3^{\mathrm{a}}$ e $4^{\mathrm{a}}$ ordens apresentam respectivamente $85(148,56 \mathrm{~km}), 43(72,18 \mathrm{~km}), 30$ $(55,70 \mathrm{~km})$ e $11(17,09 \mathrm{~km})$ segmentos de canais fluviais, os quais correspondem - por sua vez - a um total de 169 canais com extensão de 293,54km. Com relação às informações apresentadas, Horton 
(1945) afirma que a ordem dos canais apresenta utilidade limitada e, por isso, utilizada para comparações simples do nível de desenvolvimento de bacias hidrográficas de tamanhos similares. Afirmações de caráter mais concreto do nível de desenvolvimento da rede de drenagem exigem a consideração de outras variáveis.

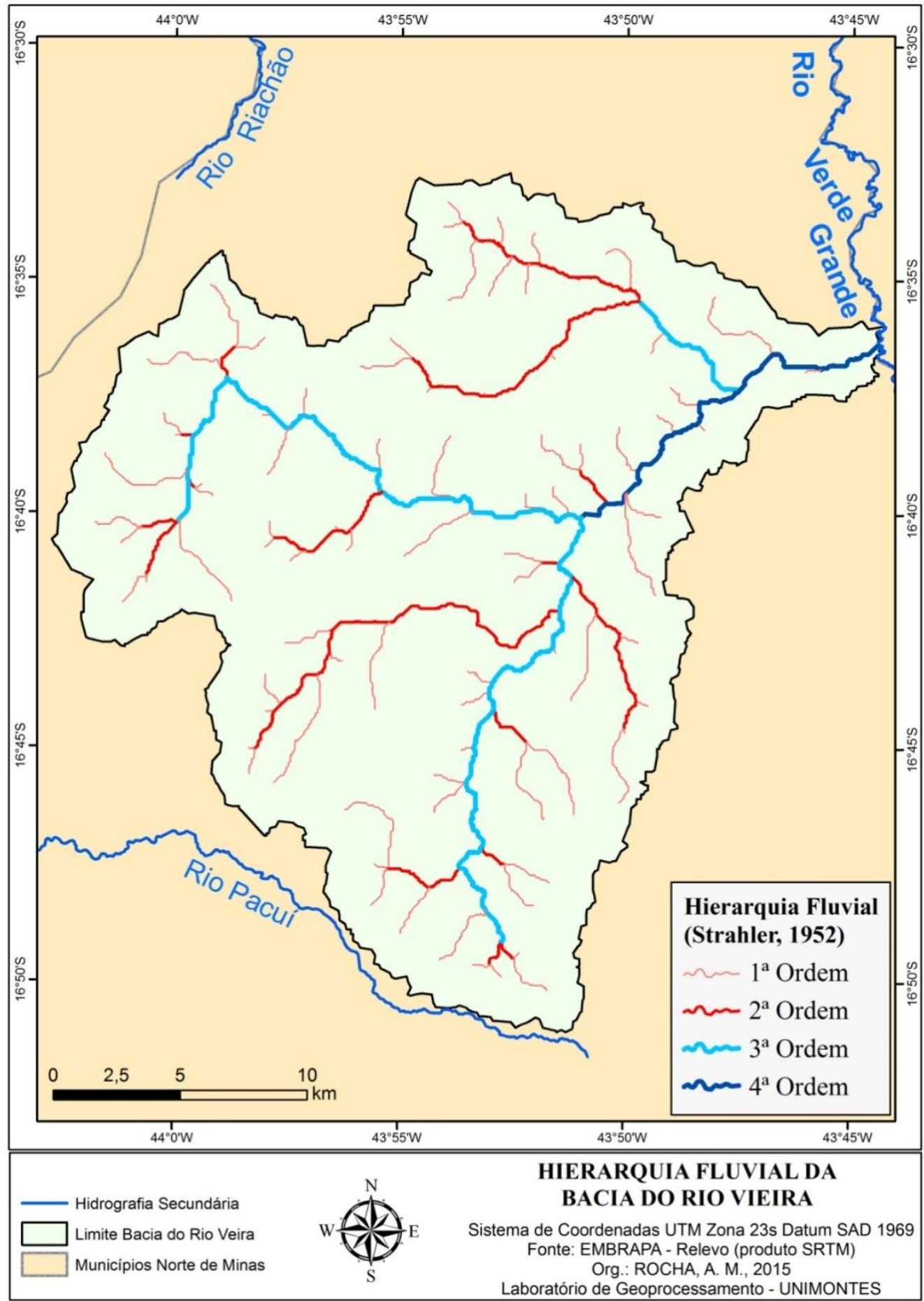

Figura 3. Classificação Hierárquica da bacia do Rio Vieira, conforme Strahler (1952). 
Dentre os parâmetros areais, a Relação de Bifurcação (Rb),inicialmente, da bacia de estudo indicou um valor médio de 2,05, o que conforme os estudos de Horton (1945), valores relativamente baixo como o mostrado acima são característicos de relevos aplainados ou relativamente ondulados. Strahler (1952), a exemplo, encontrou valores para áreas de relevo rebaixado igual a 3,55, ao passo que Horton (1945) chegou ao mínimo de 2,27 para superfícies aplainadas do Esopus Creek.

Paralelamente ao exposto, a Relação do Comprimento médio dos canais $(R l m)$ apresentou comportamento de forma diferente do enunciado pela $2^{\text {a }}$ lei de Horton (1945), no qual os comprimentos dos canais das ordens inferiores para as superiores tenderiam a seguir uma série geométrica direta e, no entanto, o comprimento dos canais aparenta diminuir com o aumento da ordem. Assim, os valores alcançados deixam transparecer que, embora os canais de $1^{\mathrm{a}}$ ordem possuam menor nível de desenvolvimento hidrológico, os mesmos apresentaram-se mais extensos que os canais de $4^{\mathrm{a}}$ ordem a qual sugerem por outro lado maior desenvolvimento.

A variável Relação do Gradiente de Canais $(R g c)$, por sua vez, revelou de forma antecipada o aspecto relativamente aplainado da superfície da bacia do rio Vieira, a qual possui em média canais com declive de 2,9\%. A Tabela 1 permite averiguar que mesmo os canais de $1^{\text {a }}$ ordem, a qual alcançam em determinados pontos inclinação de $40 \%$ possuem média de declividade igual a $3,5 \%$, evidenciando que a rede de drenagem se constitui relativamente plana e, por isso, tende a apresentar baixa velocidade no escoamento fluvial e atividade erosiva pouco intensa. Tais características tornam-se mais evidentes à medida que se aproxima dos canais de $4^{\mathrm{a}}$ ordem.

A Extensão do Percurso Superficial (Eps) da bacia do rio Vieira encontrada foi 0,988 km (ou 988m) e tal valor significa que a distância percorrida pelo escoamento superficial desde o interflúvio até a concentração no canal é relativamente longa. A afirmação acima resulta da relação inversa existente entre a Dd e a Eps apresentada por Horton (1945). Logo, a interpretação antecipada do baixo valor de Dd da bacia do Rio Vieira (poucos canais por unidade de área) revela que o caminho traçado pelo escoamento na superfície desde o interflúvio é alta e consequentemente fornece pistas na qual apontam 
que os vales da bacia de estudo são alargados e pouco aprofundados, sendo seus interflúvios locados a distâncias consideráveis, quando comparados entre si. Por outro lado, tendo por base os limiares entre os altos e baixos valores de Dd indicados por Villela e Mattos (1975), a bacia de estudo seria caracterizada com pequeno valor de Eps (isto é, índice menor ou igual a 142m), caso sua Densidade de Drenagem fosse da margem de $3,5 \mathrm{~km} / \mathrm{km}^{2}$ ou superior. No entanto, as análises posteriores revelaram exatamente o oposto.

Em continuidade, o Índice de Sinuosidade $(I s)$ foi calculado e o canal principal da bacia do rio Vieira apresentou valor de 1,6, o que conforme Lana, Alves e Castro (2001), tal valor remete a canais transicionais, regulares ou irregulares. No entanto, cabe ressaltar que a rede de drenagem extraída do MDE tende a apresentar certo nível de retilização dos canais e por isso embora o valor do $I s$ seja 1,6 , espera-se que o nível de meandramento do canal seja superior ao calculado. Como exemplo, o referido índice para o mesmo rio, porém extraído da carta de 1:100.000 (IBGE), a qual credita-se mais proximidade do delineamento real do rio em relação ao MDE, revelou valor de 1,8, indicando dessa forma maior sinuosidade.

\section{Análise Linear}

Os cálculos morfométricos da bacia do Rio Vieira indicaram-na com área de $580,1 \mathrm{~km}^{2}$, perímetro de $142,5 \mathrm{~km}$ e comprimento de $33,4 \mathrm{~km}$. Aliado a tais valores, o índice de circularidade encontrado foi de 0,35, a qual conforme Lana, Alves e Castro (2001), tal informação permite concluir que a forma da bacia distancia da área de um círculo, sendo dessa forma alongada e pouco propensa a ocorrência de cheias.

Por conseguinte, a Densidade de Drenagem $(D r)$ da bacia do rio Vieira calculada foi de $0,50 \mathrm{~km} / \mathrm{km}^{2} \mathrm{e}$ com relação a tal valor, Villela e Mattos (1975) afirma que densidades próximas a 0,5 são características de áreas pobremente drenadas. 
Com relação ao Coeficiente de Manutenção, o valor encontrado foi de $1.975,99 \mathrm{~m}^{2} / \mathrm{m}$ (ou $1,97 \mathrm{~km}^{2} / \mathrm{km}$ ), significado que cada metro de canal fluvial exige uma área mínima de $1975 \mathrm{~m}^{2}$ para sua manutenção. De outro modo, interpretando o limiar do fluxo de acumulação, tem-se que cada pixel (de $900 \mathrm{~m}^{2}$ ) da bacia apresenta minimamente área convergente de $1,90 \mathrm{~km}^{2}$.

\section{Análise Hipsométrica}

A bacia do rio Vieira possui amplitude altimétrica de $472 \mathrm{~m}$, sendo seu ponto de menor altitude localizado a $564 \mathrm{~m}$ na confluência com o rio Verde Grande e o ponto de maior altitude situado a $1.036 \mathrm{~m}$ no setor sudeste da bacia, na micro-bacia do Córrego dos Bois. A área de estudo apresenta altitude média de 769,4m, com desvio padrão de 107,6m e coeficiente de variância de $14 \%$. Tais dados possibilitam concluir que a distribuição das altitudes da bacia não apresenta alta dispersão, indicando que os mesmos estão relativamente concentrando no entorno da média apresentada. O histograma, representado na Figura 4, permite avaliar a distribuição dos 644.524 pixels que contemplam a bacia do rio Vieira, podendo concluir a existência dois grandes polos de acumulação, entre as faixas de 650$700 \mathrm{~m}$ e $800-850 \mathrm{~m}$.

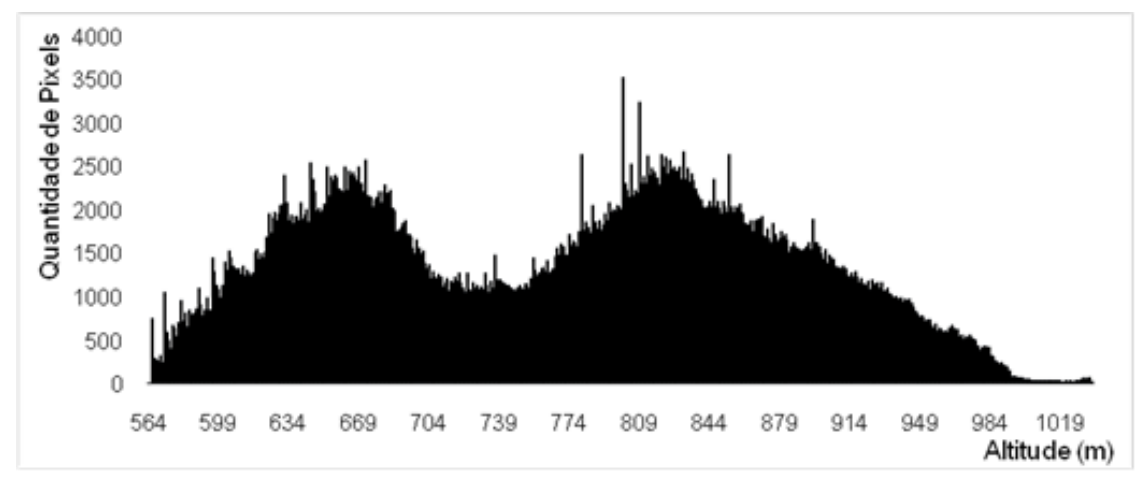

Figura 4. Histograma da hipsometria da Área de Estudo.

A tabela 2 abaixo reforça a idéia dos dois pólos de concentração da hipsometria da bacia. De outro modo, a tabela ainda permite concluir que cerca de $83 \%$ da bacia está localizada entre as altitudes de 600 a 900m. Altitudes superiores a 900m estão restritas a áreas de divisores topográficos situadas no limite da bacia e entre os afluentes de margem esquerda do rio principal. Por outro lado, altitudes inferiores a $600 \mathrm{~m}$ são encontrados somente nos trechos do rio Vieira localizados a jusante da confluência com seu afluente rio do Cedro. 
Tabela 2. Distribuição das classes Hipsométricas da Bacia do Rio Vieira.

\begin{tabular}{ccc}
\hline \multirow{2}{*}{ Classes } & \multicolumn{2}{c}{ Área } \\
\cline { 2 - 3 } & $\mathbf{k m}^{\mathbf{2}}$ & $(\boldsymbol{\%})$ \\
\hline 564 a 600 & 24,107 & 4,2 \\
600 a 650 & 77,196 & 13,3 \\
650 a 700 & 94,694 & 16,3 \\
700 a 750 & 52,988 & 9,1 \\
750 a 800 & 74,310 & 12,8 \\
800 a 850 & 105,133 & 18,1 \\
850 a 900 & 79,235 & 13,7 \\
900 a 950 & 51,211 & 8,8 \\
950 a 1036 & 21,198 & 3,7 \\
\hline Total & 580,072 & 100,00 \\
\hline
\end{tabular}

A declividade (Tabela 3), por sua vez, confirmou que a bacia do rio Vieira apresenta quase $90 \%$ de sua área em declives inferiores $20 \%$ (ou $12^{\circ}$ ), com concentração na faixa entre 3 a $8 \%$. As referidas fases do relevo conforme a EMBRAPA $(2009)^{4}$ correspondem a áreas de topografia pouco movimentada e declives de suave a moderado. Por outro lado, os declives superiores a $20 \%$ estão localizados, principalmente em áreas de vertentes ou relevo escapado da porção oeste da bacia, podendo em alguns casos chegar a inclinações de $77 \%$ (ou aprox. $33,8^{\circ}$ ). No entanto, tais declives possuem representação de somente $10,2 \%$ da área de estudo.

Tabela 3. Distribuição das classes Hipsométricas da Bacia do Rio Vieira.

\begin{tabular}{lcc|c}
\hline \multirow{2}{*}{ Classes } & Relevo & \multicolumn{2}{c}{ Área } \\
\cline { 3 - 4 } & & $\mathbf{k m}^{\mathbf{2}}$ & $\mathbf{( \% )}$ \\
\hline 0 a $3 \%$ & Plano & 88,382 & 15,24 \\
3 a $8 \%$ & Suave Ondulado & 238,100 & 41,05
\end{tabular}

\footnotetext{
${ }^{4}$ Embora Florenzano (2008) apresente proposta de classes de declividade diferente da utilizada, a proposição da EMBRAPA (2009) foi utilizada por melhor representar a distribuição da declividade na área de estudo e por apresentar explanações mais compatíveis com a proposta do artigo.
} 


\begin{tabular}{cccc}
8 a $20 \%$ & Ondulado & 194,533 & 33,54 \\
20 a $45 \%$ & Forte Ondulado & 56,939 & 9,82 \\
45 a $75 \%$ & Montanhoso & 2,116 & 0,36 \\
$>75 \%$ & Escarpado & 0,002 & 0,02 \\
\hline & Total & 580,072 & 100,0 \\
\hline
\end{tabular}

Fonte: EMBRAPA, 2009.

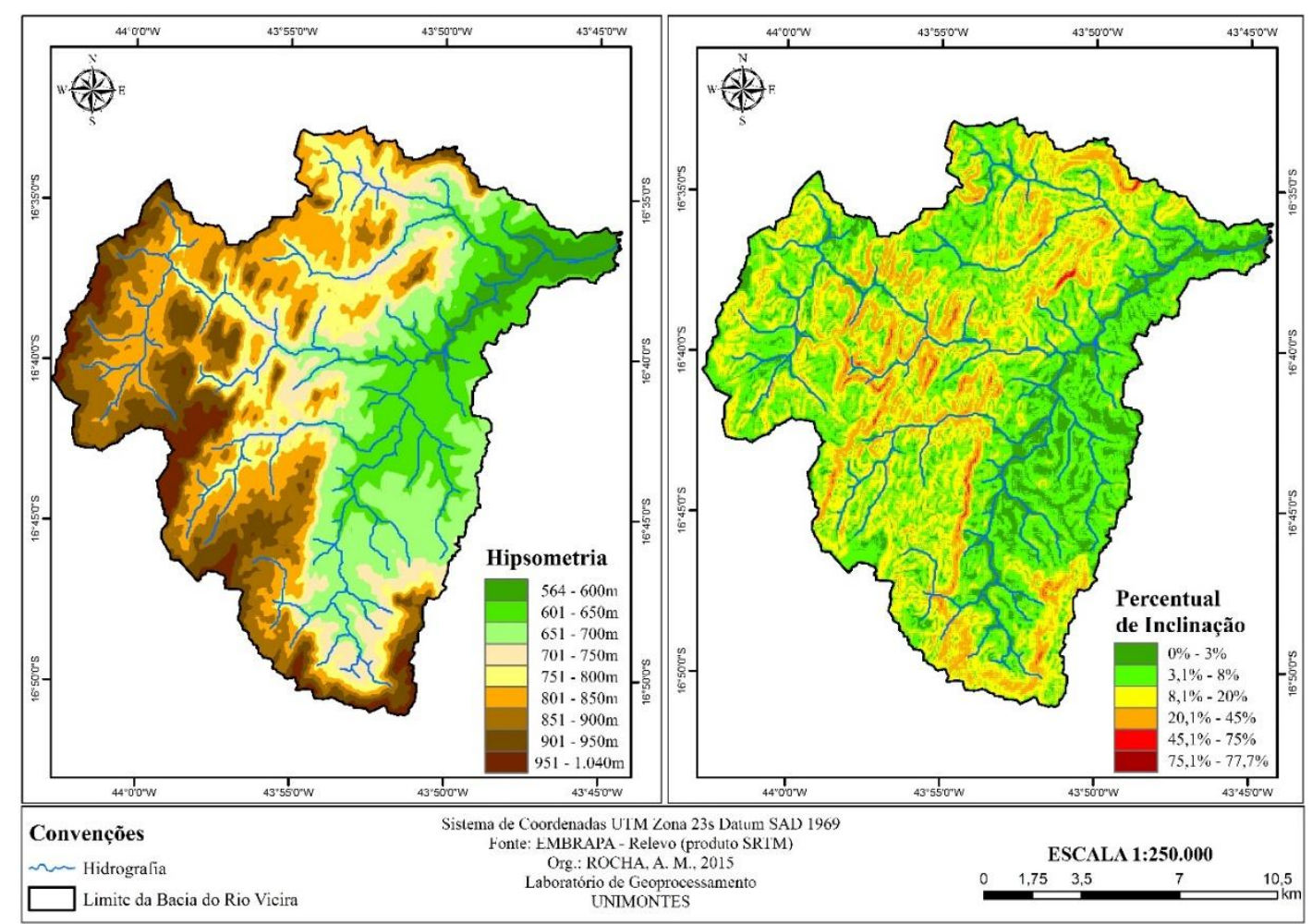

Figura 5. Hipsometria e Declividade da bacia de Estudo.

Fundamentando-se na concepção e uso da curva hipsométrica de Strahler (1957), a Figura 6 permite concluir que o traçado da curva da bacia de estudo aproxima-se mais precisamente da fase de Equilíbrio do Ciclo Erosivo do referido autor. Em tal estudo, Strahler (1957) afirma que curvas hipsométricas do Estágio de Equilíbrio remetem a superfícies em que os processos de erosão e transporte dentro do sistema fluvial atingiram sua estabilidade; sendo o sistema de drenagem com pouca tendência a expansão. 


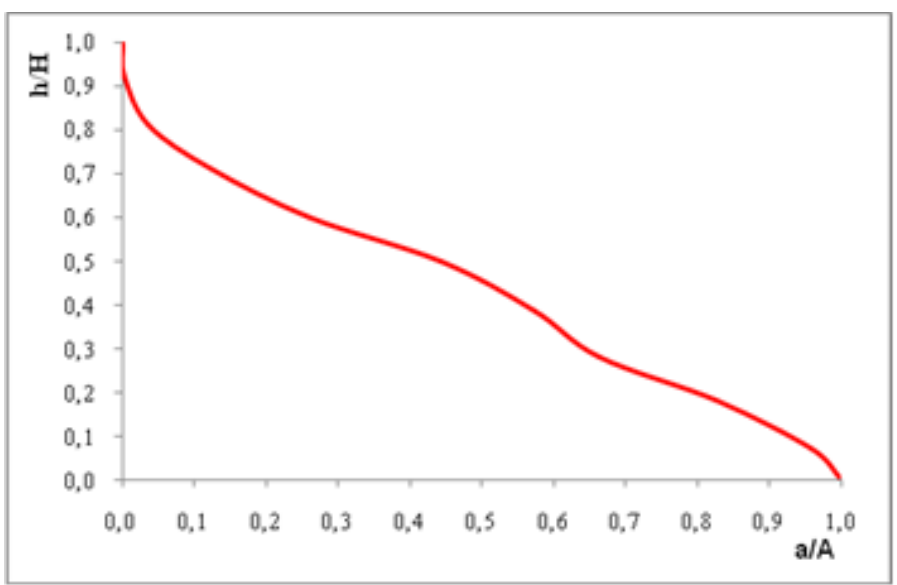

Figura 6. Curva Hipsométrica da Bacia do Rio Vieira.

De outro modo, o referido autor identificou as características acima relatadas como peculiares a bacias de $3^{\text {a }}$ a $4^{\text {a }}$ ordem, com composição litológica relativamente homogênea. Nesse ponto, observa-se que as informações apresentadas são compatíveis com a bacia do rio Vieira, visto que a mesma, diante do estudo, apresentou-se como bacia de $4^{\text {a }}$ ordem, com rochas sedimentares em sua maioria (homogeneidade litológica), relevo rebaixado e pequena amplitude altimétrica.

Com relação aos índices Relação de Relevo e Índice de Rugosidade, os mesmos apenas confirmam os aspectos hipsométricos anteriores. Em princípio, a Relação de Relevo encontrada foi de $14,11 \mathrm{~m} / \mathrm{km}$, a qual considerando o comprimento máximo da bacia, um desnível de $11 \mathrm{~m}$ ocorre a cada $1 \mathrm{~km}$. Leite, Almeida e Silva (2012), como exemplo, encontraram para a bacia do Rio Pacuí que apresenta relevo mais rebaixado que a do Vieira e forma mais alongado valor de $5 \mathrm{~m} / \mathrm{km}$.

Os dados apresentados assim permitem concluir que a Bacia do rio Vieira apresenta maior $R r$ em relação a bacia do rio Pacuí devido apresentar superfície levemente mais inclinada. O Índice de Rugosidade encontrado para a bacia de estudo foi de 238,82 e considerando a densidade de drenagem da bacia ser relativamente baixa (valor $0,5 \mathrm{~km} / \mathrm{km}^{2}$ ), característica de superfícies pobremente drenadas e apresentar pouca variação da amplitude altimétrica, o valor alcançado no Ir sugere um valor relativamente baixo. 
Diante dos resultados alcançados, verificou-se que os parâmetros morfométricos propostos permitiram extrair importantes informações sobre o grau de desenvolvimento da bacia de drenagem do rio Vieira. Nesse ponto, observou-se que os indicadores apresentaram compatibilidade entre si com relação às informações extraídas. Em primeiro plano, os baixos valores da Rb, Rge, Dd, Ic e Declividade indicaram que a bacia possui relevo predominantemente entre o aplainado e o ondulado, com sistema de drenagem fracamente drenado, com poucas ramificações e baixa propensão a cheias. Em continuidade, o alto índice Eps e baixo Ir sugerem que os interflúvios da bacia estão situados a certa distância quando comparados entre si, sendo seus vales pouco aprofundados e vertentes alongadas. A curva hipsométrica, por fim, confirmou as características indicadas pelos índices anteriores, no qual o estágio de equilíbrio do ciclo erosivo representa a nítida estabilidade alcançada pela atividade erosiva e de outro modo dos atributos associados à rede de drenagem da bacia.

\section{CONSIDERAÇÕES FINAIS}

Diante da proposta elencada, cabe ressaltar que os resultados obtidos se fazem exclusivamente em função da utilização de recursos de SIG, a qual propiciou a extração de informações necessárias aos cálculos morfométricos. Porém, deve-se enfatizar que embora o MDE oriundo da missão SRTM tenha se mostrado eficaz nas análises realizadas a partir da reamostragem para a resolução espacial de 30m, validações da rede de drenagem, a partir de imagens de satélite e pesquisas de campo não podem ser desconsideradas, visto que conforme apontado em estudos de Strahler (1952) e Horton (1945), o delineamento fidedigno da rede de drenagem da bacia de estudo é fundamental para que o cálculo dos demais parâmetros morfométricos possa refletir as reais características geomorfológicas da bacia de drenagem. De outro modo, cabe ressaltar que a sistematização de parâmetros morfométricos sugeridas por Christofoletti (1980) apresentou-se eficiente diante da proposta de análise, por propiciar a caracterização do nível de desenvolvimento da rede de drenagem, assim como o estágio da atividade erosiva da bacia de estudo. Ademais, a sistematização utilizada potencializa-se por reunir os principais índices sugeridos por Horton (1945) e Strahler (1952 e 1957), no que se refere à proposição de análise do relevo de bacias hidrográficas. No entanto, para estudos posteriores, os demais índices 
encontrados nos estudos de Florenzano (2008), Melton (1958), Miller (1953) e Schumm (1956), assim como de Horton (1945) e Strahler (1952 e 1957) propriamente são decerto complementares para estudo de caráter mais aprofundado do nível de desenvolvimento de bacias de drenagem.

\section{Agradecimentos}

Os autores agradecem o apoio financeiro da FAPEMIG, através das bolsas de pesquisa.

\section{REFERÊNCIAS}

CHEREM, L. F. Análise morfométrica da bacia do Alto Rio das Velhas - MG. 2008. Dissertação (Mestrado em Modelagem de Sistemas Ambientais) - Instituto de Geociências, Universidade Federal de Minas Gerais - IGC/UFMG, 111 p. Belo Horizonte, 2008. Disponível em: < http://csr.ufmg.br/modelagem/dissertacoes/luizfelipecherem.pdf >. Acesso em novembro de 2014.

CHRISTOFOLETTI, A. Geomorfologia. 2. ed. São Paulo: Edgard Blücher, 1980.

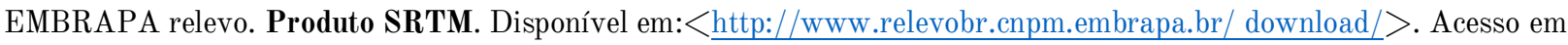
novembro de 2014.

EMBRAPA. Sistema Brasileiro de Classificação de Solos. - Rio de Janeiro: EMBRAPA-SPI, 2009. Disponível em: <http://www.bdpa.cnptia.embrapa.br/>. Acesso em dezembro de 2013.

IBGE. Mapa Municipal de Montes Claros. Disponível em: $<$ http://mapas.ibge.gov.br/bases-e-referenciais/basescartograficas/mapas-municipais $>$. Acesso em novembro de 2014.

KLINKENBERG, B.; SCHIEFER, E.; HAM, D. GIS. In: GOUDIE, A. S. Encyclopedia of Geomorphology. EUA: Routledge, 2006. p.441-444. Disponível em:

<http://earthweb.ess.washington.edu/ess6/links/GoudieEncyclopediaofGeomorphology.pdf >. Acesso em novembro de 2014

FLOREnZANO, T. G. Geomorfologia: conceitos e tecnologias atuais. São Paulo: Oficina de Textos, 2008.

GUERRA, A. T.; GUERRA, A. J. T. Novo Dicionário Geológico-Geomorfológico. 9. ed. Rio de Janeiro: Bertrand Brasil, 2011.

HORTON, R. E. Erosional development of streams and their drainage basins: Hydrographical approach to quantitative morphology. Geological Society of America Bulletin, v.56, n.2, p.275-370, 1945. Disponível em:

<http://www.geos.ed.ac.uk/homes/s0451705/horton_1945.pdf > . Acesso em novembro de 2014.

JENSON,S. K.; DOMINGUE, J. O. Extracting topographic Structure from Digital ElevationData for Geographic Information System Analysis. Photogrammetric Engineeringand Remote Sensing. v. 54. n. 11. p. 1593-1600. 1988. Disponível em: <http://m1.archiveorange.com/m/att/H2CPn/ArchiveOrange_BqIHJa44tNzoGVG7sjCxl900bao.pdf>. Acesso em Dezembro de 2013. 
LANA, C. E.; ALVES, J. M. P.; CASTRO, P. T. A. Análise morfométrica da bacia do Rio do Tanque, MG - Brasil. Revista Escola de Minas, Ouro Preto, v. 54, n. 2, p. 121-126, 2001. Disponível $\mathrm{em}:<$ http://www.scielo.br/scielo.php?script=sci_arttext\&pid=S0370-44672001000200008 $>$. Acesso em novembro de 2014

LEITE, M. E.; ALMEIDA, J. W. L; SILVA, R. F. Geotecnologias aplicadas à extração automática de Dados Morfométricos da bacia do Rio Pacuí/MG. Revista Brasileira de Cartografia. № 64/65. p. 677-691, 2012. Disponível em: <http://www.lsie.unb.br/rbc/index.php/rbc/article/view/473/502>. Acesso em novembro de 2014.

MELTON, M. A. Geometric Properties of Mature Drainage Systems and their Representation in $\mathrm{E}^{4}$ Phase Space. The Journal of Geology, v. 66, n. 1, p. 35-54, 1958. Disponível em: $<$ http://www.jstor.org/stable/30056939?seq=1\#page_scan_tab_contents $>$. Acesso em novembro de 2014.

MILLER, V. C. A Quantitative geomorphic study of drainage basin characteristics in the Clinch Mountain area Virginia and Tennessee. 1953. Disponível em:<http://www.researchgate.net/publication/235057446_A_Quantitative_Geomorphic_Study_of_Drainage_Basin_Shape _Characteristics_in_the_Clinch_Mountain_Area_Virginia_and_Tennessee $>$. Acesso em outubro de 2015.

ROCHA, A. M.; MORAIS, G.R.; LEITE, M. E. Análise Morfométrica da Bacia do Rio Vieira, Montes Claros - MG. In: XVII Simpósio Brasileiro de Sensoriamento Remoto (SBSR), 25-29 abr. 2014, João Pessoa. Anais... São José dos Campos: INPE.

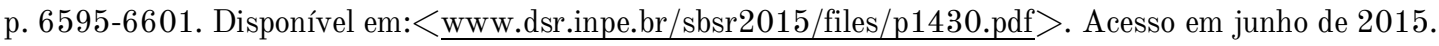

RUSZKICZAY-RUDIGER, Z. Tectonic and climatic forcing in Quaternary landscape evolution in the central Pannonian Basin: A quantitative geomorphological geochronological and structural analysis. 2007. 149p. Tese (Doutorado em Ciências Naturais) Vrije University, Amsterdã, 2007. Disponível em: $<$ http://dare.ubvu.vu.nl/handle/1871/10689 $>$ Acesso em novembro de 2014.

SCHUMM, S. A. Sinuosity of alluvial rivers on the Great Plains. Geological Society of America Bulletin, v. 74, n. 9, p. 1089-1100, 1963. Disponível em: <http://gsabulletin.gsapubs.org/content/74/9/1089.short>. Acesso em novembro de 2014.

STRAHLER, A. N. Hypsometric (area-altitude) - analysis of erosion al topography. Geological Society of America Bulletin, v.63, n.10, p.1117-1142, 1952. Disponível em:

< http://www.unc.edu/courses/2010spring/geog/591/001/students/nmey13/GE0L483/Lab5/pdfs/Strahler_1952_hypso metry.pdf $>$. Acesso em novembro de 2014

STRAHLER, A. N. Quantitative analysis of watershed geomorphology. Geophysical Union Trans., v.38, p.912-920, 1957. Disponível em:<http://www.uvm.edu/ pdodds/files/papers/others/1957/strahler1957a.pdf>. Acesso em novembro de 2014.

VALERIANO, M.M; KUPLICH, T.M.; STORINO, M.; AMARAL, B.D.; MENDES Jr., J.N.; LIMA, D.J. 2006. Modeling small watersheds in Brazilian Amazonia with shuttle radar topographic mission-90m data. Computers \& Geosciences, v.32,

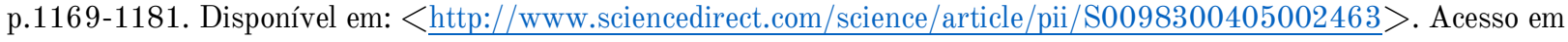
novembro de 2014.

VILELlA, S. M.; MATTOS, A. Hidrologia Aplicada. São Paulo: McGraw-Hill. 1975. 245p. 